\title{
Restoration of depressed immune function in spinal cord injury patients receiving rehabilitation therapy
}

\author{
WF Kliesch ${ }^{2}$, JM Cruse ${ }^{1}$, RE Lewis ${ }^{1}$, GR Bishop ${ }^{1}$, B Brackin ${ }^{1}$ and JA Lampton ${ }^{1}$ \\ ${ }^{1}$ The University of Mississippi Medical Center; ${ }^{2}$ The Mississippi Methodist Rehabilitation Center, Jackson, MS \\ 39216, USA
}

\begin{abstract}
Both natural and adaptive immune responses were strikingly decreased 2 weeks after injury in 49 spinal cord injuries, 28 tetraplegic and 21 paraplegic patients compared to agematched controls. All values are expressed as means. NK cell function decreased to $21.0 \% 2$ weeks after spinal cord injury compared to $48.6 \%$ in controls. At 2 weeks, plasma ACTH values increased to $17.0 \mathrm{pg} / \mathrm{ml}$ in patients compared to $11.2 \mathrm{pg} / \mathrm{ml}$ in controls and urine free cortisol levels were elevated to $162.4 \mu \mathrm{g} / 24 \mathrm{~h}$ in patients compared to $53.6 \mathrm{ug} / 24 \mathrm{~h}$ in controls. T cell function decreased to $40.2 \%$ of normal (lymphocyte transformation) by 3 months post injury. $\mathrm{T}$ cell activation (IL-2R) was diminished, i.e., $183.4 \mathrm{ug} / \mathrm{ml}$ compared to $328.2 \mathrm{ug} / \mathrm{ml}$ in controls. With rehabilitation therapy, NK cell function increased to $41.6 \%$ by 7 months post injury. NK cell-mediated lysis diminished sharply between 7 and 9 months decreasing to $22.8 \%$ at 10 months and ultimately returning to the 2 week post injury level. Rehabilitation therapy contributed to the restoration of $\mathrm{T}$ cell function to $92.0 \%$ of normal by 6 months post injury where it remained for $6+$ months. IL-2R values improved in parallel with lymphocyte transformation. Whereas NK cell-induced lysis remained depressed, i.e., $11.8 \%$ at 6 months and $11.4 \%$ at $12+$ months in patients not receiving therapy, the restoration of NK cell function at 6 months to $40.6 \%$ in rehabilitated patients decreased to $23.0 \%$ with cessation of treatment. NK cell-mediated lysis values in cervical injury patients were significantly less than those in the thoracic injury group. FIM scores of the two paralleled their NK cell function. With rehabilitation therapy, NK cell-mediated lysis in the cervical group increased from $15.2 \%$ to $28.4 \%$, whereas it improved in the thoracic group with therapy from $26.8 \%$ to $43.7 \%$. With rehabilitation therapy, lymphocyte transformation in the cervical group increased from $37.3 \%$ to $85.6 \%$ and improved in the thoracic group from $48.4 \%$ to $88.9 \%$. With rehabilitation therapy, FIM scores improved from 49.7 to 74.0 in the cervical group and from 79.8 to 97.3 in thoracic patients compared to 126 in controls of healthy age matched controls.
\end{abstract}

Keywords: paraplegia; tetraplegia; stress; NK cell function; T cell function; immunosuppression

\section{Introduction}

Previous studies in our laboratory demonstrated that spinal cord injury and stroke were followed by depression of both natural and adaptive limbs of the immune system. ${ }^{1,2}$ This was revealed by decreased NK cell-mediated lysis and diminished lymphocyte transformation/IL-2R levels, respectively. Hormonal changes accompanying these immune system alterations included elevated ACTH and increased cortisol levels in the plasma and urine. NK and T cell function improved with rehabilitation therapy from a nadir for NK cells at 2 weeks and for T cells at 3 months to the lower physiological range by 6 months after injury. This restoration of immune system function was

Correspondence: JM Cruse MD PhD, Department of Pathology, University of Mississippi Medical Center, 2500 North State Street, Jackson, MS 39216, USA accompanied by improvement in self sufficiency as reflected by elevated Functional Independence Measurement (FIM) scores in patients. The present investigation was designed to demonstrate the effects of chronic stress associated with spinal cord injury on the immune system beyond 6 months post injury. We showed restoration of immune system function through rehabilitation therapy by comparison with patients not receiving treatment. We also examined the effects of the level of the spinal cord injury on severity of immunosuppresion.

\section{Patients and methods}

All immunologic and hormonal assays were performed using standard analytical proceedures. ${ }^{1,2}$ 


\section{Study subjects}

Forty-nine patients consisting of 28 traumatic tetraplegic quadriplegic and 21 paraplegic patients volunteered to serve as the subjects of the investigation. The spinal cord injury patients included both males and females with a mean age of 25 years. Peripheral blood samples were drawn two weeks following injury in the spinal cord patients to give sufficient time for catabolism of initial corticosteroid injections, to prevent interference with cortisol assays. Subsequent blood samples were drawn at designated intervals as shown in the Results section. Thirty-two healthy age matched subjects served as controls. Eight subjects not receiving rehabilitation therapy following cervical spinal cord injury also served as controls.

Upon admission to the spinal injury services of Mississippi Methodist Rehabilitation Center, patients had first a complete evaluation of medical problems such as pulmonary infection and chest wall restriction. Diaphragmatic strengthening was begun immediately. Any skin problems affecting patients, such as pressure ulcers, were addressed, and urinary tract infections were treated. As soon as possible, patients were started on an intermittent catheterization program. Efforts were made to obtain reflex voiding in males. Females, if at all possible, were taught self catheterization. The neuropathic bowel was addressed with a program to assure adequate evacuation without infection and retraining of the bowel to obtain a predictable evacuation program. In Occupational Therapy the patients were trained in the performance of activities of daily living. Upper extremity range of motion, strengthing, and endurance were emphasized. Physical therapy addressed lower extremity range of motion, mobility training, whether on the wheelchair level or walking, muscle strengthening, balance training and transfers. Proper equipment was provided for mobility.

The patient had extensive psychological and social intervention to help with adjustment both from the social service department and also from psychologists and psychiatrists as needed. Recreation therapy gave the patients a chance to socialize and to test their newly acquired skills in the community. The patients' length of stay depended on their initial presenting diagnosis and degree of disability. Under ideal circumstances, the patients would be able to care for themselves.

\section{FIM score determination}

Functional independence measurement (FIM) scores were determined for each patient on a serial basis based on such factors as self care with respect to eating, grooming, bathing, dressing, toileting, sphincter control including bladder and bowel management, mobility, locomotion, communication and social cognition including social interaction, problem solving and memory. Levels of functional independence measurement include: (1) total assistance, (2) maximum assistance, (3) moderate assistance, (4) minimum assistance, (5) supervision, (6) modified independence and (7) complete independence. Levels 1 through 5 require a helper for the individual whereas level 6 and 7 require no helper. ${ }^{3}$

\section{Statisical analysis}

Data were analyzed using appropriate parametric statistical analysis. Data are presented as means \pm standard errors of the mean (SEM). All means were calculated from determinations obtained from individually tested subjects. The two-tailed $t$ test was used to compare various values obtained from subjects to normal healthy age matched controls. Correlation coefficients were utilized to represent parallel or inverse trends in the data.

\section{Results}

\section{Effect of spinal cord injury on natural immunity}

Figure 1 depicts the functional assay for natural killer cells, derived from the peripheral blood of 49 patients. The mean value for NK cell-induced lysis was $21.0 \%$ $(P<0.01)$, which represents NK cell function 2 weeks after injury. Thus, NK cell function diminished to approximately one-half of normal in injured subjects, as determined by comparison with healthy age-matched controls whose NK cell-induced lysis values ranged from $39-62 \%$ lysis with a mean of $48.6 \%$. Except for a slight elevation at 1 month, NK cell-mediated lysis decreased to $19.7 \%(P<0.01)$ by 2 months post injury. Thereafter, NK induced lysis increased with time reaching a peak of $41.6 \%$, which is in the lowest range of normal, at 7 months post injury. NK cell function declined precipitously between 7 and 9 months diminishing to a mean value of $22.8 \%$ $(P<0.01)$ at 10 months. Even though there was a slight rise in mean NK cell-mediated lysis in the following 2 months, NK cell function ultimately returned to the greatly depressed level first seen at 2 weeks post injury.

Figure 1 also depicts changes in urine free cortisol in $24 \mathrm{~h}$ urine specimens from study subjects. Levels reached a mean of $162.4 \mu \mathrm{g} / 24 \mathrm{~h}(P<0.01)$ in patients at two weeks post injury compared to a mean urine free cortisol level of $53.6 \% \mu \mathrm{g} / 24 \mathrm{~h}$ in controls. Following a brief elevation at 1 month, urine free cortisol levels diminished to a mean value of $137.6 \mu \mathrm{g} /$ $24 \mathrm{~h}(P<0.05)$ by two months post injury. At three months, the mean level peaked at $226.1 \mu \mathrm{g} / 24 \mathrm{~h}$ $(P<0.01)$. Thereafter, it decreased with time to a normal mean value of $66.3 \mu \mathrm{g} / 24 \mathrm{~h}$ by 6 months post injury. The urine free cortisol level remained in the normal range between 6 months and 1 year after injury. Creatinine measurements were made to control for proper $24 \mathrm{~h}$ urine collection.

Plasma ACTH levels showed quantitative variations from normal, i.e., a mean of $17.0 \mathrm{pg} / \mathrm{ml}(P<0.01)$ in spinal cord injury patients at 2 weeks post injury compared to a mean of $11.2 \mathrm{pg} / \mathrm{ml}$ in controls. ACTH values paralleled elevations and declines in cortisol levels $\quad(r=0.88, \quad P<0.01) ; \quad($ Figure 2$)$. Although 


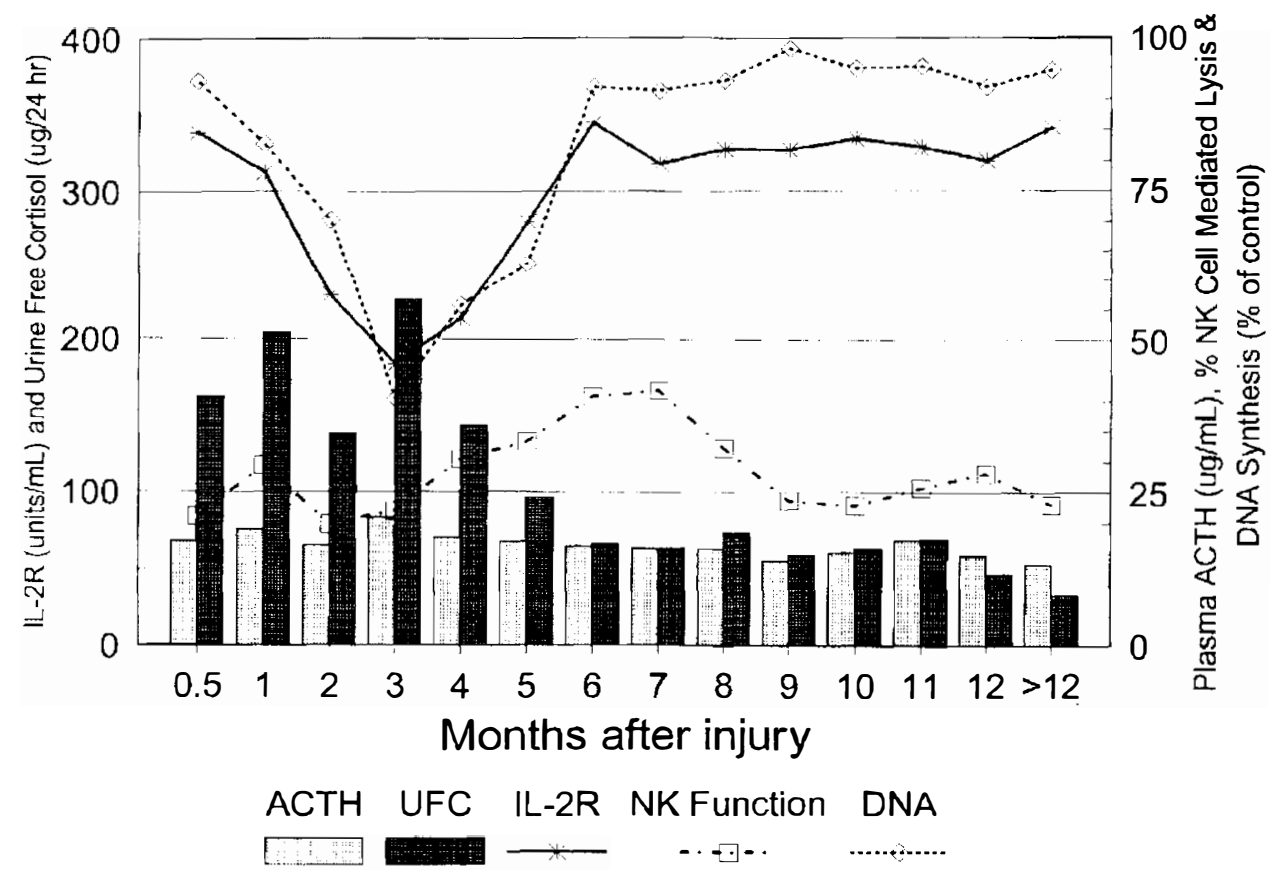

Figure 1 Alterations in Natural Killer (NK) cell function and T cell function (DNA synthesis) compared to interleukin 2-receptor (IL-2R), urine free cortisol (UFC) and adrenocorticotropic hormone (ACTH) levels in the same patients with time. Patient data are presented as means

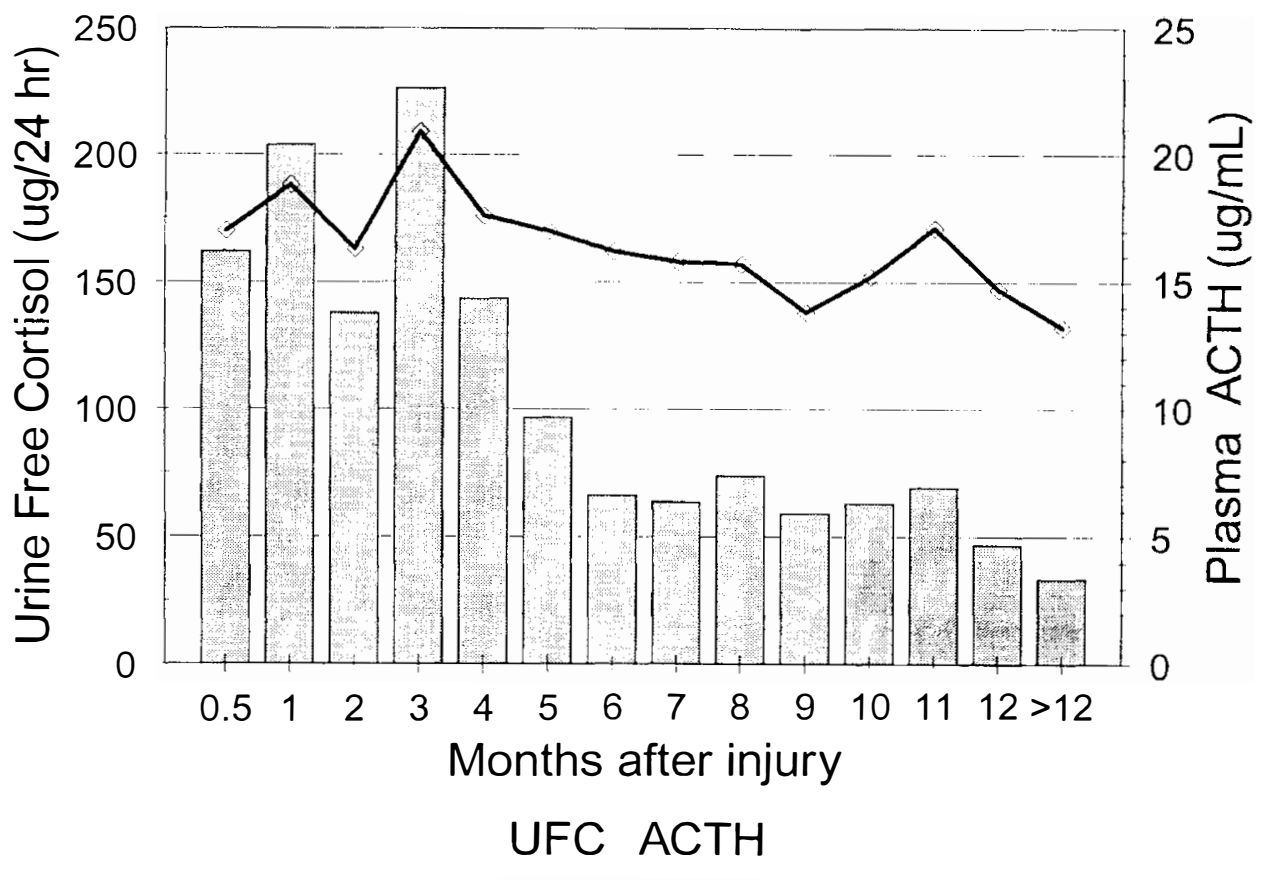

Figure 2 Comparisons of plasma adrenocorticotropic hormone (ACTH) and urine free cortisol (UFC) levels in spinal cord injury patients with time. Patient data are presented as means 
reference values for plasma ACTH levels are somewhat higher, our control group yielded values ranging from 10.5 to $12 \mathrm{pg} / \mathrm{ml}$. There was a slight rise in ACTH level between 2 weeks and one month post injury followed by a decrease to $16.3 \mathrm{pg} / \mathrm{ml}$ at 2 months. By 3 months, plasma ACTH peaked at $20.9 \mathrm{pg} / \mathrm{ml}$ (mean) $(P<0.01)$ followed by a steady decline to $16.2 \mathrm{pg} / \mathrm{ml}(P<0.01)$ by 6 months post injury. Plasma ACTH values remained only slightly elevated between 2 weeks and 8 months post injury with the 9 month, 12 month, and $12+$ month values falling in the upper range of normal.

Effect of spinal cord injury on adaptive immune function As depicted in Figure 3, T lymphocyte function as measured by lymphocyte transformation induced by Leukoagglutinin, principally a $\mathrm{T}$ cell mitogen, showed a significant decline beginning at 2 weeks post injury diminishing from $92.5 \%$ of normal to $40.2 \%(P<0.01)$ at 3 months post injury. $\mathrm{T}$ cell function increased gradually over the next 3 months to $92.0 \%$ of normal (mean) by 6 months post injury. The restoration of adaptive immune function as reflected by lymphocyte transformation was sustained between 6 and 12 months post injury and thereafter. Also depicted in Figure 3, cortisol values varied inversely with $\mathrm{T}$ cell function $(r=-0.70, P<0.01)$, as reflected by DNA synthesis in lymphocyte transformation.

A second measure of $T$ cell function in the same patients was the assay of IL-2 receptors, which reflects $\mathrm{T}$ lymphocyte activation. ${ }^{17}$ As depicted in Figure 4, there was a parallel relationship between IL-2R and lymphocyte transformation values throughout the observation period of 2 weeks to $12+$ months post injury $(r=0.95, P<0.01)$.

\section{Alterations in lymphocyte subset numbers in spinal cord} injury patients

CD56 + large granular lymphocytes (NK cells) were relatively low, i.e. 5-8\%, compared to controls whose values ranged between 5 and $17 \%$ (Figure 5). As shown in Figure 5, NK cell numbers, varied only quantitatively, but in parallel with $\mathrm{NK}$ function $(r=0.66, \quad P<0.01)$, within the physiological during the observation period of 2 weeks to $12+$ months post injury.

Alterations of immune system function at 6 months and 12 months post injury in patients not receiving rehabilitation therapy

As shown in Figure 5, NK cell function was restored to the lowest limits of normal by 6 months post injury in patients receiving rehabilitation therapy (mean of $40.6 \%$ ). Their $\mathrm{T}$ cell function was also restored to the physiological range at this time (mean of 92\%). By contrast, NK cell function diminished precipitously by 12 months post injury reaching depressed values resembling those 2 weeks after injury (i.e., $23.0 \%$, $P<0.05)$. Yet the restoration of $\mathrm{T}$ cell function was sustained at 1 year post injury in these individuals.

Patients not receiving therapy experienced sustained depression of NK cell-mediated lysis with a mean of

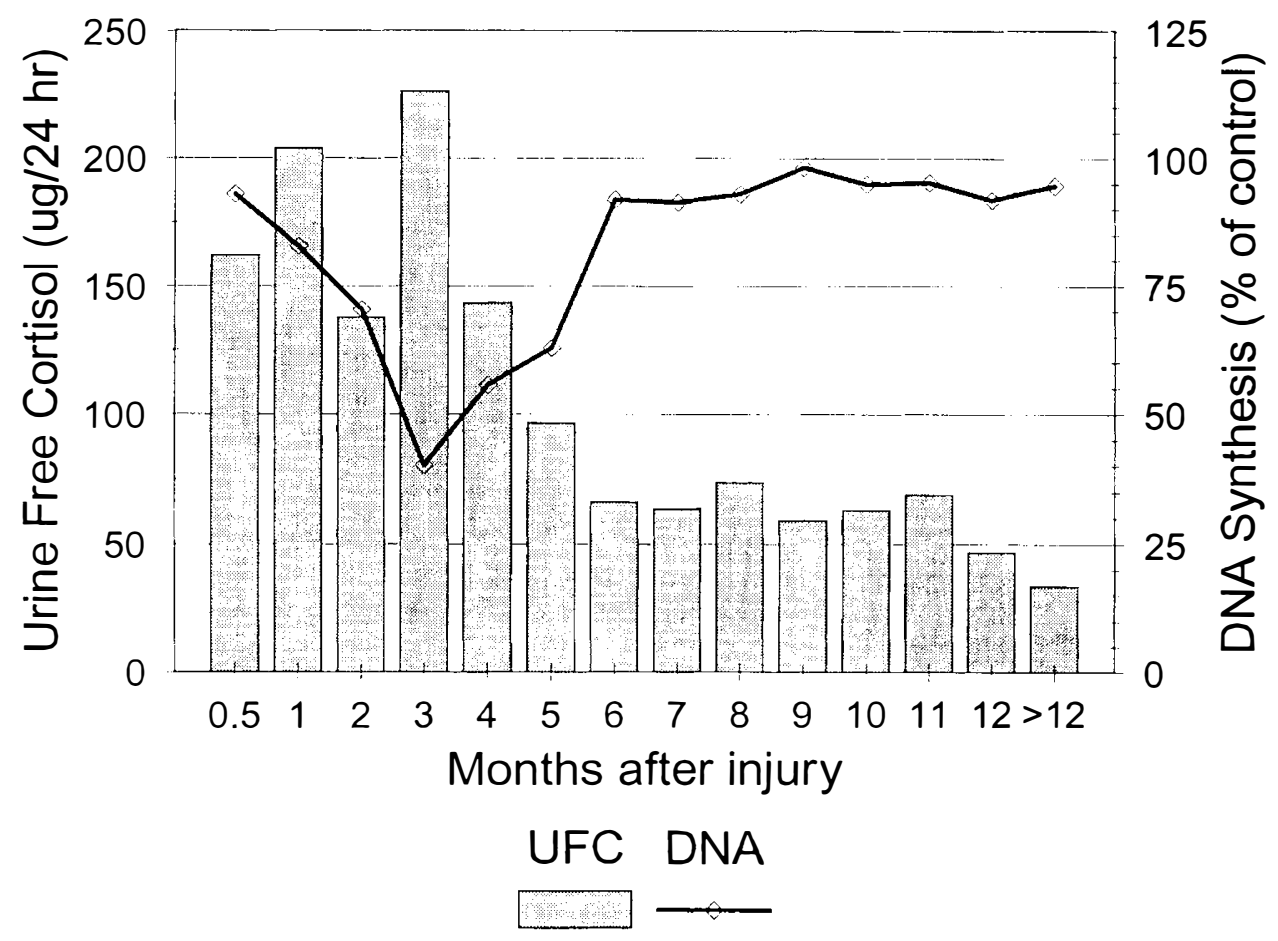

Figure 3 Alterations in $\mathrm{T}$ cell function, as determined by Iymphocyte transformation (DNA synthesis) induced by Leukoagglutinin compared to urine free cortisol levels in the same patients. Patient data are presented as means 


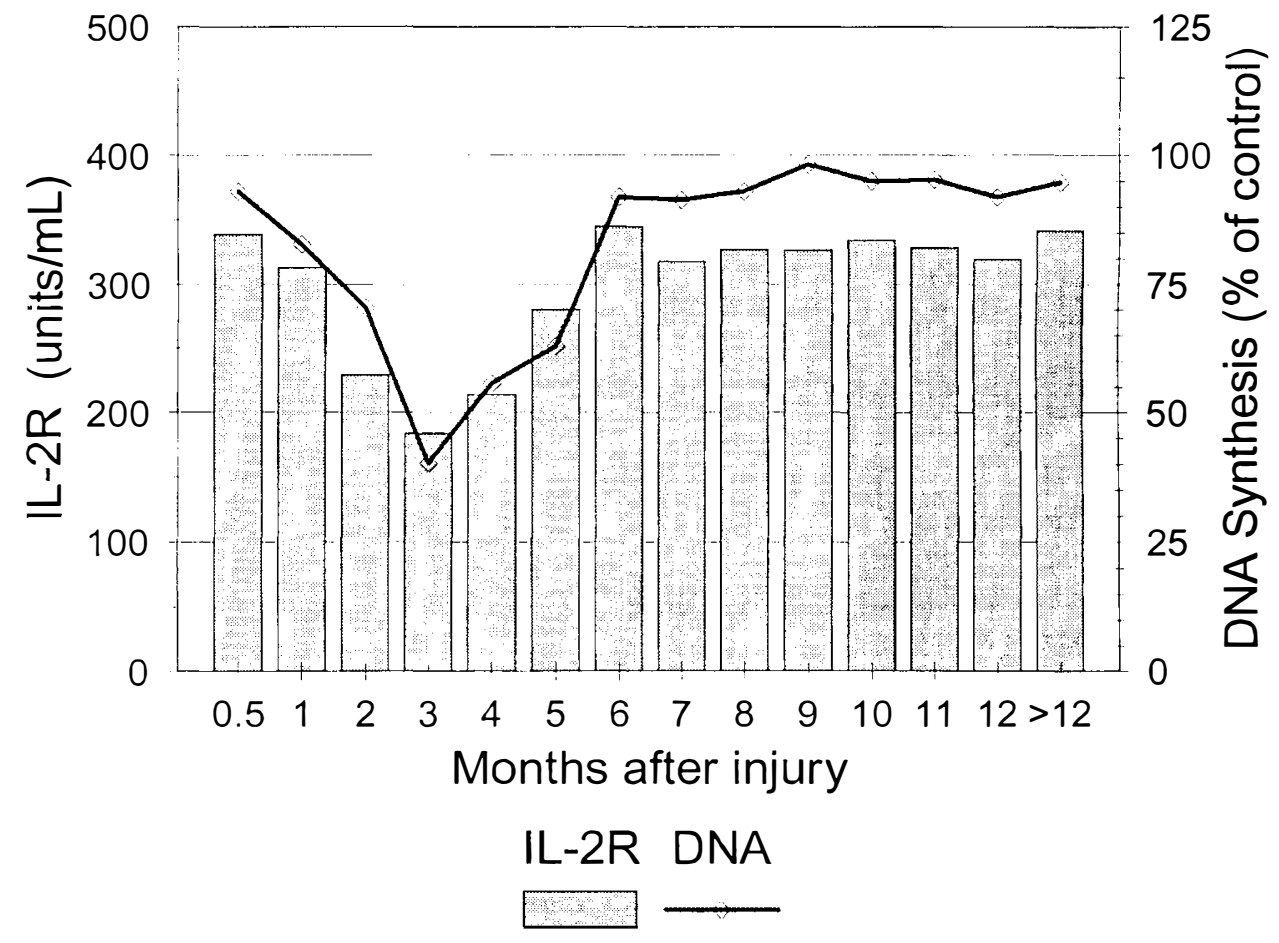

Figure 4 Comparison of $\mathrm{T}$ cell function, as determined by lymphocyte transformation (DNA synthesis) induced by Leukoagglutinin, with $\mathrm{T}$ cell activation, as reflected by interleukin-2 receptor (IL-2R) levels in serum. Patient data are presented as means

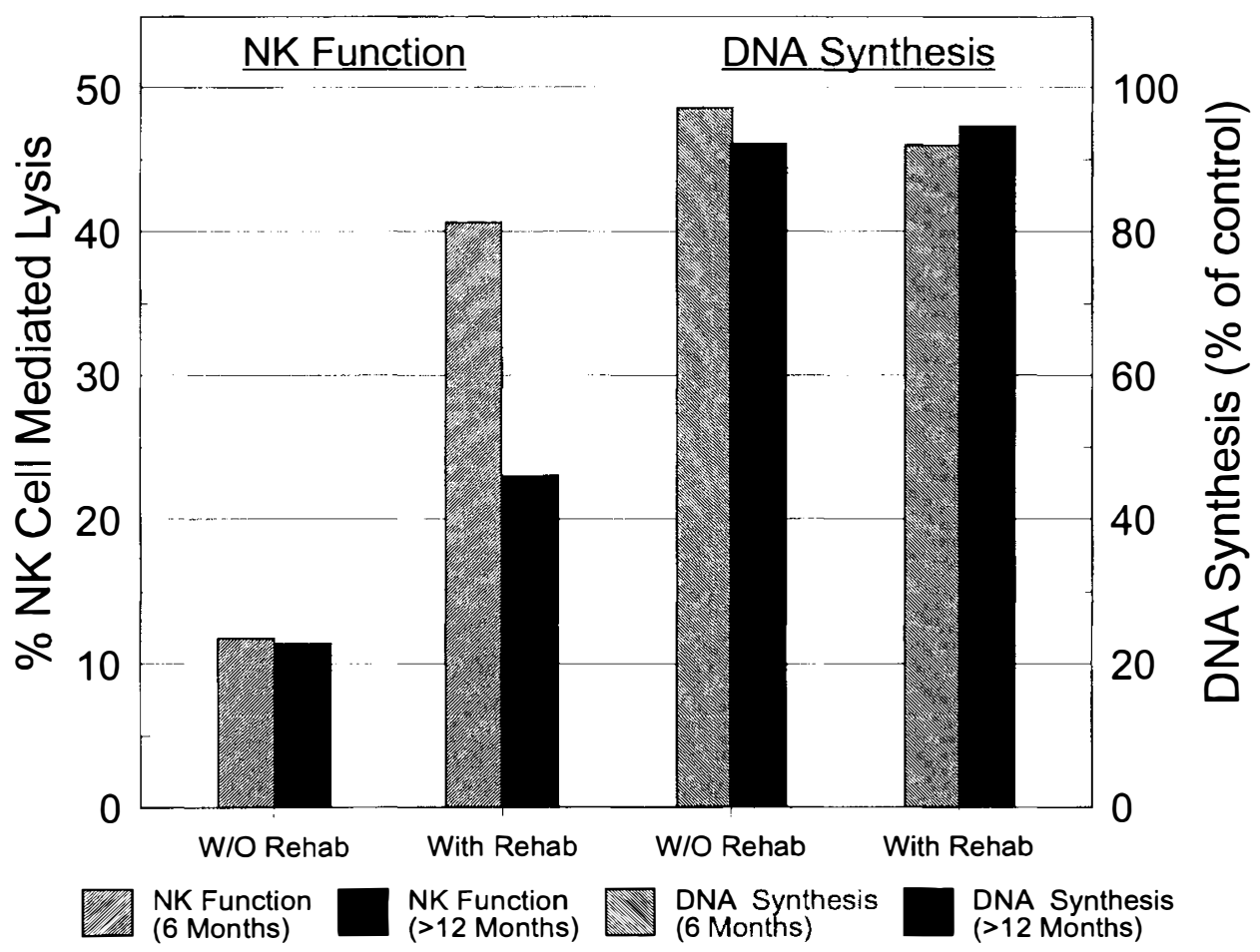

Figure 5 Alterations in Natural Killer (NK) cell and T cell function with time in spinal cord injury patients receiving and not receiving rehabilitation therapy. Patient data are presented as means 
$11.8 \%$ lysis $(P<0.05)$ at 6 months and a mean of $11.4 \%$ lysis $(P<0.05)$ at $12+$ months after injury (Figure 5). By contrast, lymphocyte transformation values remained at physiological levels.

\section{Correlation of spinal cord injury level with effect of} rehabilitation therapy on immune system function and FIM score

Whereas initial reports grouped all levels of spinal cord injury in a single population, consideration of cervical and thoracic levels of spinal cord injury separately revealed significant differences. Cervical and thoracic spinal cord injury patients were compared before and after rehabilitation therapy without consideration of time post injury.

As depicted in Figure 6 , the $\%$ NK cell-mediated lysis in cervical spinal cord injury patients increased significantly, from an initial mean value of $15.2 \%$ $(P<0.05)$ prior to rehabilitation therapy to a mean of $28.4 \%(P<0.05)$ after treatment. The percent NK cellmediated lysis in thoracic spinal cord injury patients increased significantly, from $26.8 \% \quad(P<0.01)$ to $43.7 \%(P<0.01)$, reaching the lower range of normal (Figure 7).

Cervical spinal cord injury patients showed depressed $\mathrm{T}$ cell function, i.e. $37.3 \% \quad(P<0.01)$, as reflected by lymphocyte transformation induced by con A, principally a $\mathrm{T}$ cell mitogen. With rehabilitation therapy, their lymphocyte transformation values improved markedly reaching a mean of $85.6 \%$ of normal (Figure 6). The thoracic spinal cord injury group followed a similar course with a mean lymphocyte transformation value of $48.4 \%(P<0.01)$ prior to rehabilitation therapy to a mean of $88.9 \%$ of normal after treatment (Figure 7).

As shown in Figure 6, cervical spinal cord injury patients' FIM scores improved significantly from a mean of $49.7(P<0.01)$ prior to rehabilitation therapy to a mean of 74.0 after treatment compared to 126 (mean) for normal healthy controls. Thoracic spinal cord injury patients' FIM scores were less depressed of $79.8(P<0.01)$ than were those of the spinal cord injury group prior to rehabilitation therapy (Figure 7). Nevertheless, their FIM scores improved to a mean of 97.3 following treatment. In contrast, the 8 study subjects not receiving rehabilitation therapy maintained FIM scores less than 50.

\section{Discussion}

Results show that both natural and adaptive immune system function, as determined by appropriate in vitro assays, was decreased significantly in spinal cord injury patients. This was correlated with increased urine free cortisol levels resulting from adrenal gland stimulation by elevated plasma ACTH secreted by the pituitary. NK cell function, representing natural immunity, declined precipitously to one-half normal by 2 weeks post injury and reached its lowest point by 2 months post injury. Lymphocyte transformation, representing the adaptive immune response, declined to its lowest level at 3 months. Thus, at three months post injury

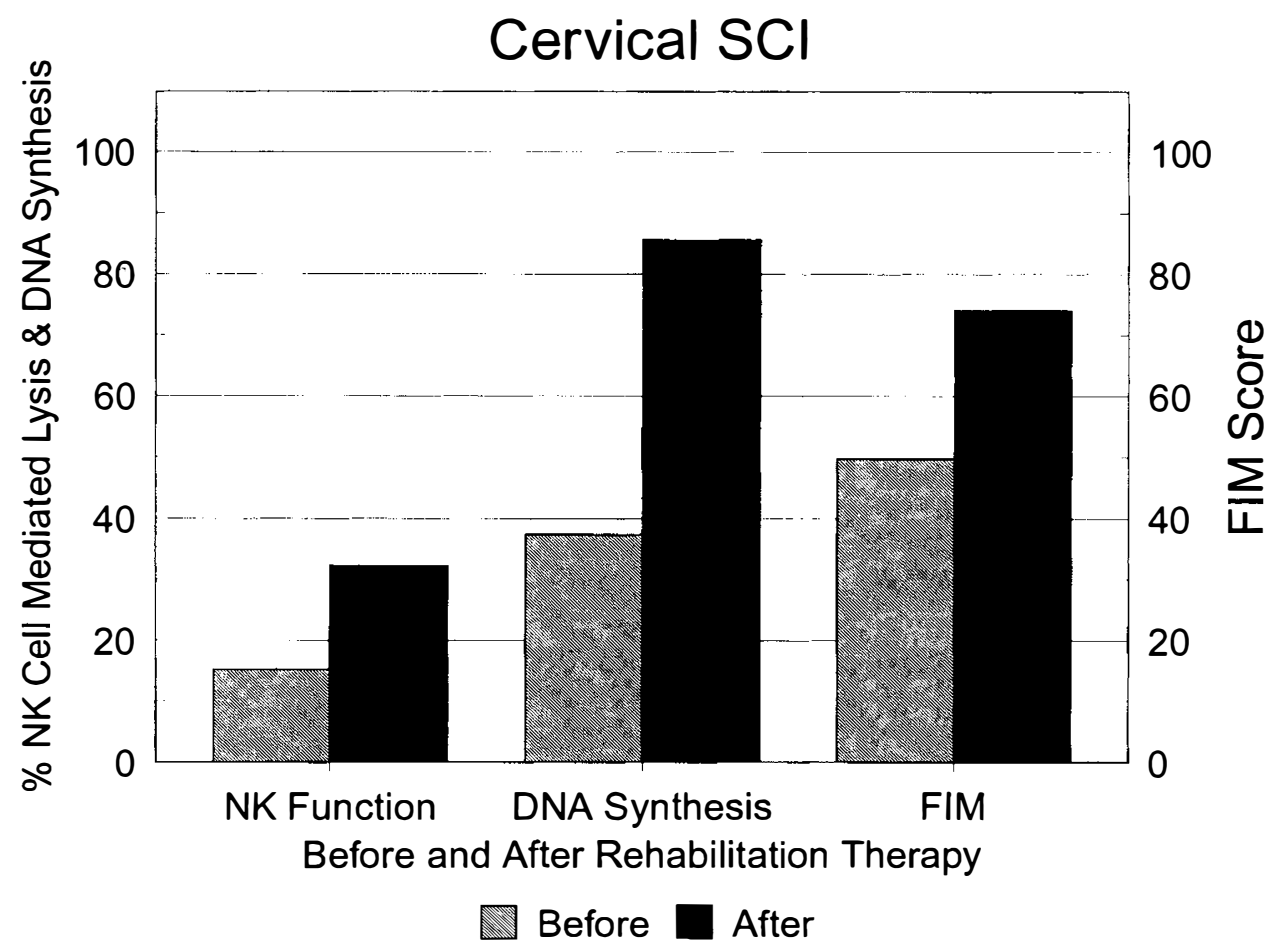

Figure 6 Comparison of Natural Killer (NK) cell and T cell function with FIM scores of cervical spinal cord injury patients before and after rehabilitation therapy. Patient data are presented as means 


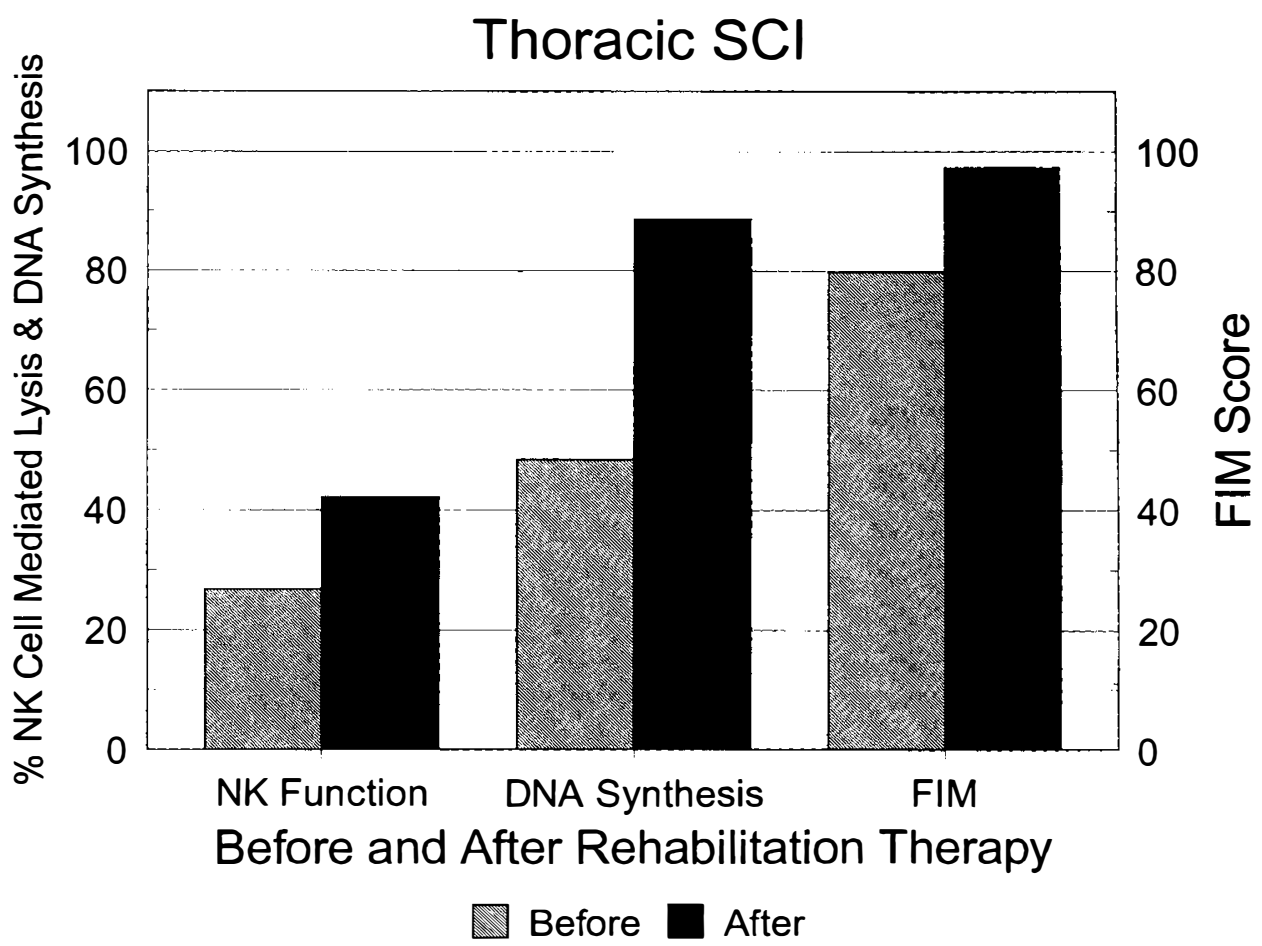

Figure 7 Comparison of Natural Killer (NK) cell and T cell function with FIM scores of thoracic spinal cord injury patients before and after rehabilitation therapy. Patient data are presented as means

the phylogenetically older NK cell system showed greater susceptibility to the stress related event of spinal cord injury or stroke than did the $\mathrm{T}$ cell system. NK cell function was slower to recover than was $\mathrm{T}$ cell function. However, both returned to the physiological range by 6 months post injury.

Most spinal cord injury patients received rehabilitation therapy during the first 6 months post injury. Results indicate that rehabilitation therapy was influential in the restoration of both natural (NK) and adaptive ( $\mathrm{T}$ cell) immune system function. By contrast, NK cell function declined from restored values at 7 to $12+$ months to the 2 weeks post injury level once rehabilitation therapy was discontinued. $T$ cell function remained in the physiological range despite discontinuation of intensive rehabilitation therapy.

Plasma ACTH and urine free cortisol values varied significantly in study subjects compared to those in controls and were associated with alterations in both NK and $\mathrm{T}$ cell function. Callewaert et $a l^{4}$ demonstrated that subphysiological levels of cortisol functionally inactivated cloned human NK cells but failed to interfere with their proliferation. Thus, the diminished NK cell function observed in the present study is not necessarily associated with decreased NK cell numbers in stressed patients with elevated cortisol levels.

Glucocorticoids are well recognized to be highly immunosuppressive for T cells. ${ }^{5}$ This is in accord with the observed inverse relationship between urine free cortisol levels and $\mathrm{T}$ cell function, as reflected by lymphocyte transformation, and $\mathrm{T}$ cell activation, as revealed by IL-2 receptor release. Glucocorticoid hormones formed in response to stress may modulate function in the immune system. ${ }^{1,2}$ Activated lymphoid cells release a glucocorticoid-increasing factor (GIF) which might possibly increase corticosteroid levels during the immune response through action at the hypothalamic-pituitary axis.

As shown in Figures 6 and 7, FIM scores improved with rehabilitation therapy. Interestingly, this progressive improvement in functional independence generally paralleled the restoration of both natural and adaptive immune function with time post injury. In contrast to the improvement in both natural and adaptive immune function demonstrated in the 49 patients reported here, 8 subjects who received no rehabilitation therapy showed continued impairment of NK cell function at varying times post injury. The effect of rehabilitation therapy on restoration of NK cell lysis in spinal cord injury patients is exemplified by the failure of patients not receiving rehabilitation therapy (Figure 5) to improve NK cell function beyond their initial depression. Therefore, our data suggest that the total program of rehabilitation therapy at MMRC restored, in part, severely depressed immune system function of some of these patients to near normal function compared to patients who never received rehabilitation therapy.

This demonstration of immune system-hypothalamic-pituitary-adrenal axis interaction leading to immunosuppression is postulated to be, in part, a 
consequence of chronic stress associated with spinal cord injury or stroke. ${ }^{6}$ Both acute and chronic stress produce suppression of the immune system. ${ }^{7}$ Principal life stressors such as divorce, bereavement from death of a relative, depression, examination pressures among medical students, continuous care of the chronically ill and physical trauma, may lead to alterations in immune responsiveness or other adverse effects on health. ${ }^{8,9}$

Psychological stress suppresses cellular immunity through depression of NK cell activity and mitogen responsiveness of $\mathrm{T}$ lymphocytes. ' 'Stress hormones' probably rise as stress intensifies followed by an eventual adaptation in response. ${ }^{10}$

In the present investigation, spinal cord injury resulted in sudden loss of innervation of multiple organs and tissues including some responsible for immune system maturation and function. The early functional depression by 2 weeks post injury of the phylogenetically older NK cell system compared to the delayed suppression of $\mathrm{T}$ cell immunity may reflect sudden interruption of neural pathways to the phylogenetically primitive diencephalon and higher cortical centers.

There are many mediators and mechanisms whereby the nervous system and pituitary/adrenal axis may modulate immunity. One pathway for neuroimmunoregulation is humoral and is dependent upon pituitary peptides and adrenal steroid hormones. A second pathway is by direct innervation of the thymus, lymph nodes, bone marrow, appendix, Peyer's patches, and spleen. Neuroendocrine hormones have variable immunoregulatory effects mediated through specific receptors. The thymus, spleen, bone marrow and perhaps other lymphoid organs contain afferent and efferent nerve fibers. ${ }^{11}$ ACTH, endorphins, enkephalins and adrenal cortical steroids derived from the pituitary represent one direction for modulating the immune response. Stimulated lymphocytes or nonstimulated macrophages may produce neuroendocrine hormonerelated peptides, ACTH and endorphins. These substances may be counter-regulatory in a stress response.

Following the initial observation that natural killer (NK) cell function was significantly depressed in spinal cord injury patients by two weeks after injury, data were correlated with the level of spinal cord injury, i.e., cervical or thoracic. Results showed that the greatest depression of NK cell function occurred in the cervical spinal cord injury group with restoration of decreased NK cell function from an initial depression of $13.8 \%$ to a post rehabilitation of therapy mean of $32.7 \%$. By contrast, the thoracic spinal cord injury patients' NK cell function showed less severe depression with a mean of $18.7 \%$, which showed significant improvement to $40.8 \%$ following rehabilitation therapy. These data point to a possible involvement of the sympathetic nervous system. Cervical spinal cord injury patients experience a loss of motor activity and sensory perception. In addition, these patients have lost sympathetic innervation of the adrenal gland as a result of their injury. ${ }^{2}$ Thus, the effect of adrenal hormones and neurotransmitters on NK cell function represent critical targets for future investigation.

Physical rehabilitation therapy plays an important role in the restoration of this neuroimmunologic communication pathway in thoracic injury patients. This is exemplified by the near normal recovery of NK cell cytoxicity experienced by the thoracic injury group. Physical rehabilitation failed to mediate significant restoration of NK cell function in cervical spinal cord injury patients. ${ }^{13}$

It is apparent from results of the present investigation and the foregoing discussion citing the work of others that the immune, neural and endocrine systems do not act autonomously. By contrast, they are critically influenced by one another through appropriate receptor-mediator interactions. Future investigations will be directed to the elucidation of mechanisms, mediators and receptors whereby these interactions occur. Results of the ongoing investigation suggest that patients who have completed their formal course of rehabilitation therapy at the Mississippi Methodist Rehabilitation Center appear to maintain restoration of immune system function in the early post treatment period. A major future aim is to confirm and extend these observations.

\section{Acknowledgements}

The authors express genuine appreciation for the generous support of this ongoing research from The Earl and Martha Lyles Wilson Foundation, Jackson, MS, USA. Gratitude is also extended to: Ms Isabelle White, Executive Director, Wilson Foundation for her unstinting support; Professor Eduardo Gaitan, MD for advice related to endocrinological aspects of the investigation; Dr Orlando Andy MD, professor of Neurosurgery for reviewing the neurological aspects; Ms Elisa Bankester, MT(ASCP), Ms Kathy VanLandingham, MT(ASCP), Ms Paula Hymel, MT(ASCP), Ms Susan Touchstone, MT(ASCP), SBB(AABB), Ms Patsy Foley, MT(ASCP), and Ms Maxine Crawford, BS for expert technical assistance; and to Ms Berlinda Harris for exceptional skill in preparation of the manuscript for publication.

\section{References}

1 Cruse JM et al Neuroendocrine-immune interactions associated with loss and restoration of immune system function in spinal cord injury and stroke patients. Immunol Res 1992; 11: $104-116$.

2 Cruse JM et al Decreased immune reactivity and neuroendocrine alterations related to chronic stress in spinal cord injury and stroke patients. Pathobiology 1993; 61: 183-192.

3 Uniform Data System for Medical Rehabilitation. SUNY Research Foundation, Buffalo, N. Y., 1992.

4 Orth DN. Corticotropin Releasing Hormone in Humans. Endocrine Reviews 1992; 13: $164-192$.

5 Irwin, M.R., Vale, W. and Rivier, C. Central corticotropin releasing factor mediates the suppressive effect of footshock stress on natrual cytotoxicity. Endocrin $1990 ; 126: 2837-2844$. 
6 Van de Kar LD, Richardson-Morton, KD, Rittenhouse, PA. Stress: Neuroendocrine and pharmacological mechanisms. In: Jasmin, G., Cantin, M (eds): Stress Revisited. 1. Neuroendocrinology of Stress, Methods Achieve Exp. Pathol., Basel, Karger, 1991; pp. $133-173$.

7 Kort WJ, Weijma IM. Chronic stress and the immune response. In: Plotnikoff N, Murgo A, Faith R, Wybran J (eds): Stress and Immunity, CRC Press, Inc., Boca Raton, FL, 1991; pp. 523-536.

8 Workman EA, La Via MF. Stress and immunity: A behavioral medicine perspective. In: Plotnikoff N, Murgo A, Faith R, Wybran J (eds): Stress and Immunity, CRC Press, Inc., Boca Raton, FL, 1991, pp. 69-80.

9 Felten DL. Central neural circuits involved in neural-immune interactions. In: Plotnikoff N, Murgo A, Faith R, Wybran J (eds): Stress and Immunity, CRC Press Inc., Boca Raton, FL, 1991, pp. $3-25$. 